\title{
Title: Evaluation of untrustworthy journals: transition from formal criteria to a complex view
}

\author{
Authors \\ Jiří Kratochvíl, University Campus Library, Masaryk University, Brno \\ Lukáš Plch, University Campus Library, Masaryk University, Brno \\ Martin Sebera, Faculty of Sports Studies, Masaryk University, Brno \\ Eva Koritáková, Faculty of Medicine, Masaryk University, Brno
}

\begin{abstract}
Not all the journals included in credible indexes meet the ethical rules of COPE, DOAJ, OASPA and WAME and equally there may be trustworthy journals excluded from these indexes which means they cannot be used as definitive whitelists for trustworthy journals. Equally the many methods suggested to determine trustworthiness are not reliable due to including questionable criteria. The question arises whether valid criteria for identifying an untrustworthy journal can be determined and whether other assessment procedures are necessary. Since 2017, the Masaryk University Campus Library has been developing a suitable evaluation method for journals. A list of 19 criteria based on those originally suggested by Beall, COPE, DOAJ, OASPA and WAME were reduced to 10 objectively verifiable criteria following two workshops with librarians. An evaluation of 259 biomedical journals using both the list of 19 and then 10 criteria revealed that 74 journals may have been incorrectly assessed as untrustworthy using the longer list. The most common reason for failure to comply was in the provision of sufficient editorial information and declaration of article processing charges. However our investigation revealed that no criteria can reliably identify predatory journals. Therefore, a complex evaluation is needed combining objectively verifiable criteria with analysis of a journal's content and knowledge of the journal's background.
\end{abstract}

Keywords: untrustworthy journals, predatory journals, evaluation, evaluation criteria

Key points

- None of the previous methods for identifying an untrustworthy journal are effective, because they include questionable control criteria.

- In two workshops, librarians defined 122 criteria for identifying untrustworthy journals, but only 26 criteria were found to be important.

- Tests during which different sets of criteria were applied to the same journals have shown that there is a risk of misjudging a journal as untrustworthy.

- A list of 10 criteria were found sufficient for providing an indication of the trustworthiness of a journal - but any conclusion would require further investigation

- Any journal evaluation must include: a check of objectively verifiable criteria; an analysis of the journal's content, and investigation into the journal's background.

\section{Introduction}

Predatory journals and how to identify them has been discussed repeatedly in recent years (Cobey et al., 2018). Such periodicals were first noticed in 2008 (Eysenbach, 2008; Harnad, 2008) and two years later Jeffrey Beall $(2010,2016)$ named them "predatory journals". He defined approximately 50 attributes typical of such journals and until January 2017 he ran Beall's List of predatory journals and publishers. Since then a number of studies have emerged whose authors have used various terms such as deceptive and low-quality journals, illegitimate journals, deceptive journals or dark journals, and also journals operating in bad faith and they have also defined 109 possible characteristics of such journals (Cobey et al., 2018; Eriksson \& Helgesson, 2018). These journals and their publishers exploit the Gold Open Access (OA) model and do not attempt to follow the principles of transparency and best practice ("principles of transparency") in scholarly publishing in order to profit from the article processing charges (APCs) (Beall, 2016; COPE, OASPA, DOAJ, \& WAME, 2018; Rich, 2016). Many authors publish in OA journals because the conditions of the public funding of their research require it (Baruch, Ghobadian, \& Özbilgin, 2013; European Commission, 2017) or in order to improve their professional prestige arising from the accessibility of their research to the general public and from an increase in citations (Clements, Daigle, \& Froehlich, 2018; Gargouri et al., 2010; Rupp et al., 2019). It is therefore vital for scholars to distinguish between reputable OA journals, and the predatory ones (Clements et al., 2018; Darbyshire, McKenna, Lee, \& East, 2017; Olivarez, Bales, Sare, \& van Duinkerken, 2018; Yeates, 2017). 
Some studies have recommend using Beall's List as a blacklist of predatory journals and publishers and databases such as Web of Science, Scopus, MEDLINE or DOAJ as whitelists (Darbyshire et al., 2017; Hansoti, Langdorf, \& Murphy, 2016; McCann \& Polacsek, 2018; Shahriari, Grant-Kels, \& Payette, 2016). Other studies suggest basing the journal evaluation on various criteria, such as the length of the review process, accurate information about the journal's indexing in one of the above-mentioned databases, etc. (Berger, 2017; Bowman, Saultz, \& Phillips, 2018; Cobey et al., 2018; Erfanmanesh \& Pourhossein, 2017; Gasparyan, Yessirkepov, Diyanova, \& Kitas, 2015; Hill, 2015; Kumar \& Saxena, 2016; McCann \& Polacsek, 2018; Power, 2018). Librarians should help authors in this evaluation process (Eve \& Priego, 2017; Hansoti et al., 2016; Huffman, 2017; Nolfi, Lockhart, \& Myers, 2015; Olivarez et al., 2018), since they are among the experts who are presently attempting to develop methods for journal evaluation (McCann \& Polacsek, 2018; Rele, Kennedy, \& Blas, 2017; Teixeira da Silva, 2013; Tosti \& Maddy, 2017). Unfortunately, the evaluation process is yet to be standardised and some of the attributes used to uncover predatory publishers and journals have been called into question (Cobey et al., 2018; Teixeira da Silva, 2013; Yan et al., 2018). This article discusses the validity of selected criteria used to detect predatory journals and the evaluation methods that have been suggested in the existing literature as well as the evaluation system developed and tested at our library.

\section{Questionability of criteria}

Cobey et al. (2018) have created a list of 109 criteria. However, the authors themselves simultaneously noted that some criteria are subjective. For example, untrustworthy journals are associated with a review process marked as "quick" or of a length of 2-3 weeks, but this claim was not supported by any research. (Beall, 2015; Huffman, 2017; Masten \& Ashcraft, 2016; Newland, 2016; Tosti \& Maddy, 2017; Yan et al., 2018). Equally questionable is the length of the review process based on the analysis of its usual duration (Nguyen et al., 2015; Wicherts, 2016), because while writing a review may only take a couple of hours, the whole length of the peer review process is also influenced by searching for a suitable peer reviewer or by the fact that the reviewer and editor are otherwise occupied (Huisman \& Smits, 2017; McGlinchey, 2017; Schmidt, RossHellauer, van Edig, \& Moylan, 2018). Therefore, a peer review lasting only a couple of days cannot be automatically regarded as dubious editorial work.

Connecting APCs in the amount of $\$ 180$ and less with predatory practices is also problematic (Rupp et al., 2019; Shamseer et al., 2017; Shen \& Björk, 2015). Although the European Union-funded group Peere supports this claim by finding that average costs for publishing a scholarly article are between $\$ 420$ and $\$ 650$ (Centro ASK, 2011), current technology allows for low-cost journal publishing (Bowman et al., 2018; Eve \& Priego, 2017; Gasparyan et al., 2015; Gonzalez, Bridgeman, \& Hermes-DeSantis, 2018; Umlauf \& Mochizuki, 2018). Moreover, at a time when OMICS International accused by the U.S. Federal Trade Commission of predatory practices has been publishing journals with an average APC of $\$ 1,164$ (Drayton, 2019; OMICS International, c2019; Umlauf \& Mochizuki, 2018), which is close to the APCs of $\$ 1,595$ charged by PLOS ONE, a reputable OA journal (PLOS, 2019), this criterion loses its value.

Another criterion that can be called into question is the prevalence of editorial-board members from developing countries, a criterion which is based on the reasoning that the lower level of technology accessible to them means a higher risk of low-quality editorial work (Ayeni \& Adetoro, 2017; Harzing \& Adler, 2016; Kahn, 2014; Sharman, 2015). Due to the ongoing process of globalisation, it is only natural that the number of representatives from developing countries on OA journals' editorial boards is on the rise (Harzing \& Adler, 2016). Furthermore, similar to the length of the peer review, it is unclear who would be qualified to determine the highest acceptable number of editorial-board members from developing countries and how, in order to set the boundary between predatory and regular journals.

Similarly, the quality of the journal's web design is another subjective criterion (Nobes, 2017), since the websites of reputable journals can also be visually fragmented (Eve \& Priego, 2017; Kratochvíl, Plch, \& Koritáková, 2019). For example, the website of Indian Pediatrics published by Springer Nature features a header with discordant colours and a large number of different fonts and gives the name of the journal instead of the publisher in the copyright information in the footer, which could make it appear as a predatory journal.

The criterion of mimicking titles, interpreted as an attempt on the part of a predatory journal to confuse authors and entice them to submit their work for publication (Ayeni \& Adetoro, 2017; Beall, 2015; Gonzalez et al., 2018; Masten \& Ashcraft, 2016; Power, 2018), is also questionable. The similarity between journal titles can be simply a result of the journal's narrow specialisation which makes it impossible to create an innovative title (Crawford, 2014), as illustrated by the journals Biological Research and Journal of Biological Research, which have been published for decades (Kratochvíl et al., 2019).

Another disputable criterion is the contact information of the editorial office (Gonzalez et al., 2018; Power, 2018; Shahriari et al., 2016), because with the technology available today a journal may be published from anywhere, even from someone's home. (Eve \& Priego, 2017; Gasparyan et al., 2015; Gonzalez et al., 2018). 
For example, a general email service has been used by the former editor-in-chief David Raitt as well as by the current editor Marie Bloechle both from The Electronic Library published by Emerald (Emerald Publishing, c2019). Although the physical address of the editorial office can be verified through various tools such as Google Street View (Yan et al., 2018), the map data may be obsolete.

The examples mentioned above sufficiently illustrate the need to subject the validity of each criterion to critical assessment as well as the attempts to standardise journal evaluation methods.

\section{Evaluation methods}

Despite various attempts, there is no standardised methodology for journal evaluation or an agreed description of characteristics typical of predatory journals (Cobey et al., 2018; Teixeira da Silva \& Tsigaris, 2018; Yan et al., 2018). Although the databases Web of Science, Scopus or DOAJ are recommended as whitelists (Erfanmanesh \& Pourhossein, 2017; Gasparyan et al., 2015; Kumar \& Saxena, 2016; McCann \& Polacsek, 2018; Nolfi et al., 2015; Yan et al., 2018), they cannot be used because journals from Beall's List also appear in these databases (Macháček \& Srholec, 2017; Shamseer et al., 2017; Somoza-Fernández, Rodríguez-Gairín, \& Urbano, 2016; Sorokowski, Kulczycki, Sorokowska, \& Pisanski, 2017; Strinzel, Severin, Milzow, \& Egger, 2019). Beall's List can also be challenged due to a lack of transparency, the incomplete nature of his list, and his prejudice against journals from the Global South (Berger, 2017; Bloudoff-Indelicato, 2015; Crawford, 2014; Gasparyan et al., 2015; Huffman, 2017; Olivarez et al., 2018; Teixeira da Silva \& Tsigaris, 2018; Umlauf \& Mochizuki, 2018) - the doubts cast on the suitability of the above-mentioned databases as whitelists remain (Neylon, 2017).

This is confirmed by studies evaluating how journals comply with various criteria. Shamseer et al. (2017) found that journals that failed to meet some of the criteria evaluated by them are found on Beall's List, as well as among OA journals from PubMed, and among subscription titles. Kratochvíl et al. (2019) found that only 4 out of 259 biomedical Open Access journals indexed in Journal Citation Reports (JCR) meet all 14 criteria evaluated.

Neither does the whitelist and blacklist by Cabell's International offer a perfect solution, because despite Cabell's statements about transparency and annual review of all journals (Bisaccio, 2018; Power, 2018), their lists contain journals with a two-year-old review (Anderson, 2017; Plch \& Kratochvíl, 2018). Moreover, the criteria evaluated (Toutloff, 2019) include the disputable criteria mentioned above, for example, the length of the review process, a prevalence of editorial-board members from developing countries, and mimicking titles. Finally, the service has proven too costly compared to in-house journal evaluation performed by a library and the content of Cabell's blacklist partially corresponds to Beall's List and journals stricken out from DOAJ (Anderson, 2017; Bisaccio, 2018; Plch \& Kratochvíl, 2018; Teixeira da Silva \& Tsigaris, 2018).

Under these circumstances, a standardised method of evaluating journals is needed, but all the solutions suggested so far fall short of this goal. Teixeira da Silva (2013) suggested a scoring method for journal evaluation where the journals would be given plus or minus points based on whether they met selected criteria. However, he failed to explain why his scoring system attributed a different number of points to certain criteria: for example, a journal would receive three points for double-blind peer review, but only one point for open peer review although the question of the respective advantages and disadvantages of individual types of peer review remains open (Wicherts, 2016). Similarly, no reason is provided for why the "international board" criterion uses $75 \%$ as the threshold value to meet the criterion, which on top of that does not reflect the existence of high-quality local journals with a local editorial board. Furthermore, some of the criteria are difficult to verify, including sending email invitations to scholars asking them to publish in the journal or to become members of its editorial board. Teixeira da Silva (2018) later challenged some of the criteria himself when he questioned why APCs of $\$ 150$ or less or submitting an article via email should be signs of predatory journals and pointed out that even prestigious journals sometimes fail to meet all the criteria.

Rele et al. (2017) published a Journal Evaluation Tool with criteria divided into three separate categories evaluated on a 3-2-1 scale. Even this tool, however, includes questionable criteria. For example, the journal index criterion does not take into account that journals are under no obligation to be indexed in any database, and these authors would award them only one point if they are not. The fact that three points are awarded for a journal's indexation in the Google Scholar search engine or in an untrustworthy database such as Index Copernicus can also be called in question (Cortegiani, Sanfilippo, Tramarin, \& Giarratano, 2019; Kratochvíl et al., 2019; Ross-White, Godfrey, Sears, \& Wilson, 2019). The criterion number of published articles (why three points for ten articles or more and not a different number?) is also questionable.

Dadkhah and Bianciardi (2016) have suggested a scoring system, which Tosti and Maddym (2017) adopted. In this system, the final number of points received for individual criteria is divided by the number of criteria evaluated. A journal with a score of 0.22 or more is deemed predatory, while a journal with a score of $0.01-0.22$ uses some predatory practices. However, this simple and user-friendly system lacks an explanation 
for the method of calculation. Furthermore, non-transparent journals paradoxically benefit from this method since a criterion cannot be used and counted towards the divisor total if the particular piece of information is missing. In addition, Dadkhah and Bianciardi do not justify the specifics of the criteria used, such as why a journal fails to meet the review-time criterion if the review time is shorter than one week (as opposed to two weeks, for example) or why the criterion of the number of members of the editorial-board is not met when the board has five of fewer members (and not six or fewer members, for example). Moreover, the review-time criterion contains a methodical error, since the evaluator could select either of two options for a review time shorter than seven days - "Lower than a week" or "Lower than a month". The authors of the method do not give any definition of bogus metrics and they penalise journals for publishing special issues or requesting a publication fee, even though both are common features of OA journals. Lastly, this scoring system does not use some crucial criteria, such as inaccurate information about the journal's indexing or full-text availability.

Unfortunately, even the method presented by the web portal Think. Check. Submit. ('Think. Check. Submit', c2019; Yeates, 2017) is problematic. For example, a possible answer to "Are articles indexed in services that you use?" may be Google Scholar, whose search results include untrustworthy journals (Ross-White et al., 2019). Also the question "Do you or your colleagues know the journal?" could be problematic even for an experienced author, as they might have unwittingly published in untrustworthy journals as well (Bagues, Sylos Labini, \& Zinovyeva, 2017; Lucia, 2017). In other words Think. Check. Submit. aims correctly for a complex evaluation of a journal, but without offering possible answers accompanied with explanations, the risk of evaluating an untrustworthy journal as a trustworthy one remains.

McCann and Polacsek (2018) have developed a flow chart, which contains Yes/No answers and explanations for every question. Unfortunately, this journal evaluation system fails as well, because it relies uncritically on JCR and Scopus as whitelists and does not specify the term "fast peer review". Moreover, the authors' claim that a journal not indexed in the International Academy of Nursing Editors (INANE) or Scimago Journal \& Country Rank (SJR) could be predatory ignores the fact that a number of quality journals are not indexed in either of these databases - SJR is based on the content of Scopus, which does not include many respected journals indexed in Web of Science (Mongeon \& Paul-Hus, 2016).

\section{Our evaluation method}

In January 2017, our library started offering our researchers and PhD students a service for evaluating journals with regard to their compliance with the principles of transparency and best practices. This service was created as a response to repeating requests by researchers to help them with this issue during 2016, and this service was also a response to the cancellation of Beall's List. The assessment consists of examining the website of the journal including its subordinate pages, and recently published articles, and verifying whether the information provided by the journal about its operation does not indicate a violation of some of the criteria from the principles of transparency. With each new request (124 in 2017, 45 in 2018 and 16 in 2019) we have been gaining new experience which helped us critically assess our approach, which naturally underwent further development.

From January 2017 to June 2018 we assessed journals for violating the criteria defined by Jeffrey Beall (2015) and by COPE, DOAJ, OASPA and WAME together (COPE et al., 2018). At that time, this was a completely unsystematic verification of the violation of some of the criteria, including the questionable ones. When examining the journal's website we focused mainly on the length of the review process, the completeness of the affiliation of editorial board members and how many of them come from developing countries, mimicking titles, false information about citation metrics and the journal's indexation in Web of Science and Scopus, and misleading metrics. We thus did not determine in advance what criteria to assess, but on the contrary we might have drawn a conclusion about a journal already after checking three or four criteria. At that time we did not have any standardised method that would allow for a retrospective check. In any event, we have always - during the whole time this service was provided from its introduction until today - informed the researchers that our conclusion results from evaluating formal criteria only and that it is essential that the researchers themselves assess the quality of the journal's content and decide themselves whether to submit their article to the given journal.

From the beginning, we were fully aware of the risk of evaluating a journal incorrectly based on checking formal criteria only. During the first year we were providing this service, we also understood the need to standardise our evaluation method and exclude questionable criteria. In June 2018, we thus abandoned the unsystematic evaluation based on Beall's criteria (Beall, 2015) and, after a critical assessment of criteria offered by COPE, DOAJ, OASPA and WAME (COPE et al., 2018), we created a table with 19 objectively verifiable criteria (hereinafter "ET19"), see Table 1 and Sheet 1 in Appendix. When using ET19, one point is awarded for complying with a criterion and only a journal that gains all 19 points can be considered completely transparent. 
Despite objective justification for all the parameters of individual criteria, we were still aware of the subjectivity of some of the criteria. Although we determined the parameters such as the length of the review process according to published surveys (Nguyen et al., 2015; Wicherts, 2016) or the minimal common amount of APCs according to the findings of the European Union-funded group Peere (Centro ASK, 2011), these parameters still remain - as stated above - questionable. Therefore, we excluded 9 criteria from the evaluation in June 2018 and from that time until September 2019, we evaluated 10 criteria (hereinafter "ET10R") with more detailed parameters (Table 1 and Sheet 2 in Appendix). The reasons for excluding the criteria archiving, contact details of the editor-in-chief or the editorial board, amount of article processing charges and Creative Commons licence statement was explained above. Similarly to licence terms, even the criterion of clear declaration of the Open Access mode lacks any foundation, because this mode of publishing is apparent from publication conditions in the instructions for authors. This criterion disqualifies even reputable journals such as the Journal of the Czech and Slovak Societies of Pathology, where instead of a clear declaration of Open Access mode only mentions that journal only mentions "the original articles [...] are published [...] as Open Access articles" (CLSJEP, [C2019]). The periodicity criteria were also eliminated because they have become less relevant as it became common to publish articles continuously without arranging them into issues (e.g. BioMed Central Journals) as well as publishing articles soon after the peer review. The criteria of a fictitious member of the editorial board and a description of anti-plagiarism policy were excluded as well due to the difficulty of verifying them. That is because not every institution makes a list of employees public in which one can check whether the editor really works there. Likewise, compliance with an anti-plagiarism policy cannot be verified without access to the editorial system of the journal.

After this reduction of criteria, we kept thinking about the objectivity of individual criteria and discussed it repeatedly, above all excluding the criterion review time and substituting it with the criterion questionable metrics. Although the standard length of the review process is six weeks or more according to the abovementioned studies, it can also be shorter and writing the peer review itself may only take a couple of hours (Schmidt et al., 2018; Ware, 2008). The review time does not reveal anything about the quality of editorial work (only publishing the peer reviews would do this) and therefore we stopped using this criterion as of October 2019. At that time we included another criterion instead and started checking whether journals state some of the misleading metrics on their websites, and in this way we arrived at the current evaluation table (Table 2, hereinafter "ET10M"). Due to the pressure to publish in the best journals, scientists are interested in whether the journal is connected with JCR citation metrics and they may confuse it with other metrics (Dadkhah \& Bianciardi, 2016; Samuel \& Aranha, 2018). Although Beall (2017) administered a list of misleading metrics earlier, we do not use it during our evaluation. If we find that a journal states a different metrics than JCR or Scopus, we check whether a transparent method for its calculation is provided and thus the calculation can be verified. For example, if The Journals Impact Factor copies the calculation method from Clarivate Analytics without specifying the number of years and published articles, and without making bibliographic references with citation count available, we cannot consider it a transparent metrics (Global Society for Scientific Research, c2014). Likewise, we are led to evaluate Global Impact Factor as unsuitable, because it relies on methods which are questionable due to potential subjectivity in evaluating the originality of an article and also since it awards more points to journals with the highest number of published articles (Institute for Information Resources, 2017), which ignores the varying periodicity of journals and increases the risk of information overload.

\begin{tabular}{|l|c|c|c|}
\hline Criterion name & in ET19 & in ET10R & in ET10M \\
\hline Free access to full text & $\mathrm{Y}$ & $\mathrm{Y}$ & $\mathrm{Y}$ \\
\hline Unambiguous determination of article processing charges & $\mathrm{Y}$ & $\mathrm{Y}$ & $\mathrm{Y}$ \\
\hline Description of the review process & $\mathrm{Y}$ & $\mathrm{Y}$ & $\mathrm{Y}$ \\
\hline Affiliations of editorial board members & $\mathrm{Y}$ & $\mathrm{Y}$ & $\mathrm{Y}$ \\
\hline The name of the editor-in-chief included & $\mathrm{Y}$ & $\mathrm{Y}$ & $\mathrm{Y}$ \\
\hline Unambiguous identification of the publisher & $\mathrm{Y}$ & $\mathrm{Y}$ & $\mathrm{Y}$ \\
\hline The journal states its ISSN on its website & $\mathrm{Y}$ & $\mathrm{Y}$ & $\mathrm{Y}$ \\
\hline Accurate information about the journal's citation metrics in the Web of & & & \\
Science and Scopus & $\mathrm{Y}$ & $\mathrm{Y}$ & $\mathrm{Y}$ \\
\hline Claiming indexation of the journal in WoS/Scopus & $\mathrm{Y}$ & $\mathrm{Y}$ & $\mathrm{Y}$ \\
\hline Referring to a misleading metric & & & $\mathrm{Y}$ \\
\hline
\end{tabular}




\begin{tabular}{|c|c|c|}
\hline Length of the review process & Y & $\mathrm{Y}$ \\
\hline $\begin{array}{l}\text { Declaration that archiving of journal issues is ensured (e.g. } \\
\text { PubMedCentral, CLOCKSS) }\end{array}$ & $Y$ & \\
\hline Amount of article processing charges & $\mathrm{Y}$ & \\
\hline Clear statement of Open Access & $\mathrm{Y}$ & \\
\hline Declaration of Creative Commons & $\mathrm{Y}$ & \\
\hline Description of the journal's anti-plagiarism policy & $\mathrm{Y}$ & \\
\hline A fictitious person on the editorial board & $\mathrm{Y}$ & \\
\hline Contact details of the editor or the editorial board & $\mathrm{Y}$ & \\
\hline The journal states its periodicity on its website & $\mathrm{Y}$ & \\
\hline The journal has kept its periodicity for the last three years & $\mathrm{Y}$ & \\
\hline
\end{tabular}

Table 1 - Comparison of evaluation criteria

\begin{tabular}{|c|c|c|c|c|c|c|}
\hline$\#$ & $\begin{array}{l}\text { Criterion } \\
\text { name }\end{array}$ & $\begin{array}{l}\text { Method of } \\
\text { criterion } \\
\text { verification }\end{array}$ & $\begin{array}{l}\text { Parameters for } \\
\text { criterion }\end{array}$ & $\begin{array}{l}\text { Scoring } \\
\text { system }\end{array}$ & $\begin{array}{l}\text { Points } \\
\text { awarded }\end{array}$ & $\begin{array}{l}\text { Verified at the } \\
\text { website/Description } \\
\text { of verification }\end{array}$ \\
\hline \multirow{4}{*}{1} & \multirow{4}{*}{$\begin{array}{l}\text { Unambiguous } \\
\text { determination } \\
\text { of article } \\
\text { processing } \\
\text { charges }\end{array}$} & \multirow{4}{*}{$\begin{array}{l}\text { Does the journal } \\
\text { website give the } \\
\text { exact amount of } \\
\text { article } \\
\text { processing } \\
\text { charges? }\end{array}$} & $\begin{array}{l}\text { The journal } \\
\text { states that it } \\
\text { does not collect } \\
\text { any article } \\
\text { processing } \\
\text { charges. }\end{array}$ & 1 & & \\
\hline & & & $\begin{array}{l}\text { Yes, the journal } \\
\text { gives a specific } \\
\text { final amount of } \\
\text { the charges. }\end{array}$ & 1 & & \\
\hline & & & $\begin{array}{l}\text { The amount of } \\
\text { charges is } \\
\text { unclear (for } \\
\text { example, the } \\
\text { journal states } \\
\text { the price per } \\
\text { article, adding } \\
\text { that any } \\
\text { additional } \\
\text { pages will be } \\
\text { subject to extra } \\
\text { charge without } \\
\text { specifying the } \\
\text { charge). }\end{array}$ & 0 & & \\
\hline & & & $\begin{array}{l}\text { The journal } \\
\text { does not state } \\
\text { the amount of } \\
\text { article } \\
\text { processing } \\
\text { charges. }\end{array}$ & 0 & & \\
\hline 2 & $\begin{array}{l}\text { Affiliations of } \\
\text { editorial board } \\
\text { members }\end{array}$ & $\begin{array}{l}\text { Does the journal } \\
\text { website include } \\
\text { complete } \\
\text { affiliations for all } \\
\text { editorial board }\end{array}$ & $\begin{array}{l}\text { The affiliation is } \\
\text { complete and } \\
\text { includes the } \\
\text { institution and } \\
\text { the city/country. }\end{array}$ & 1 & & \\
\hline
\end{tabular}




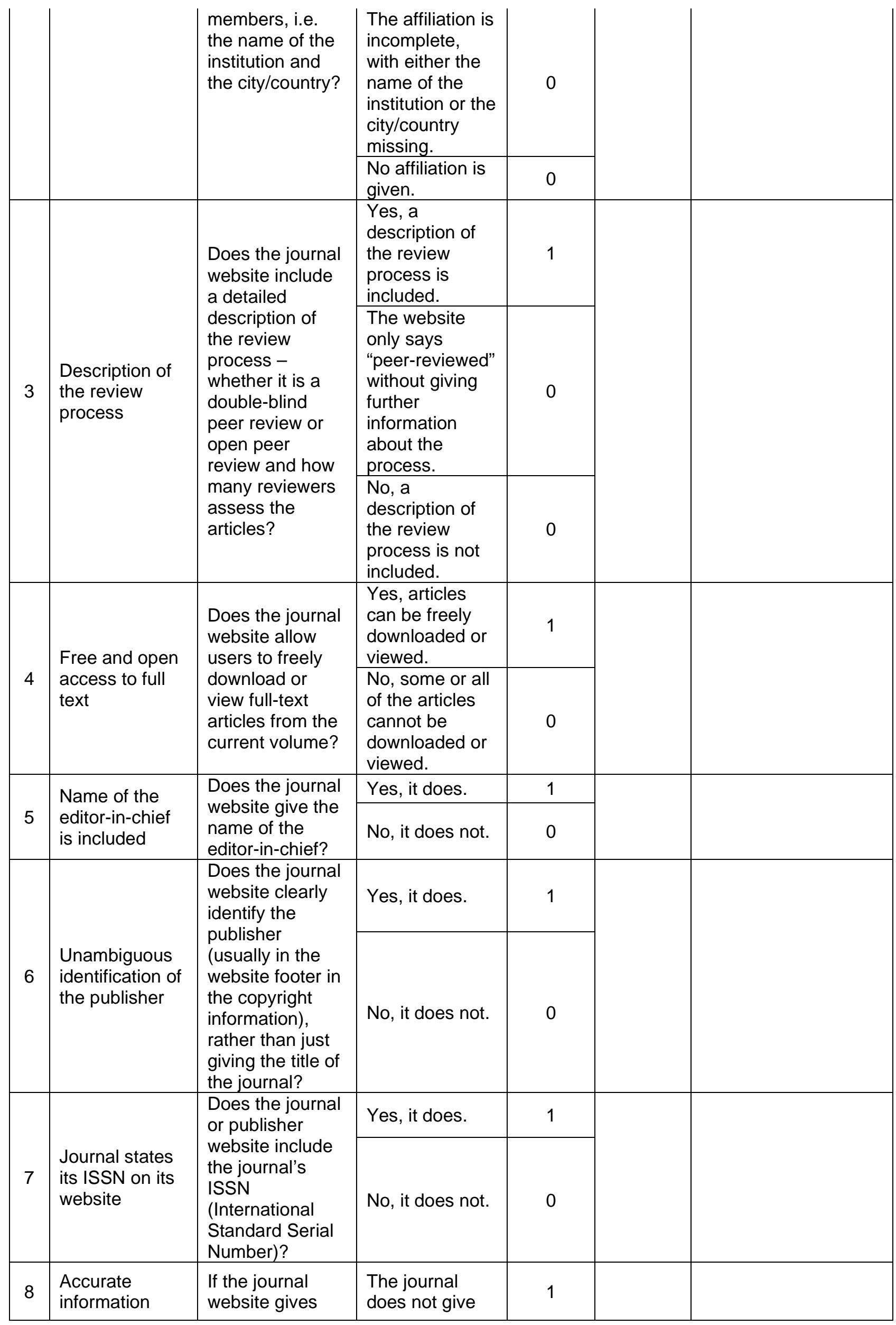




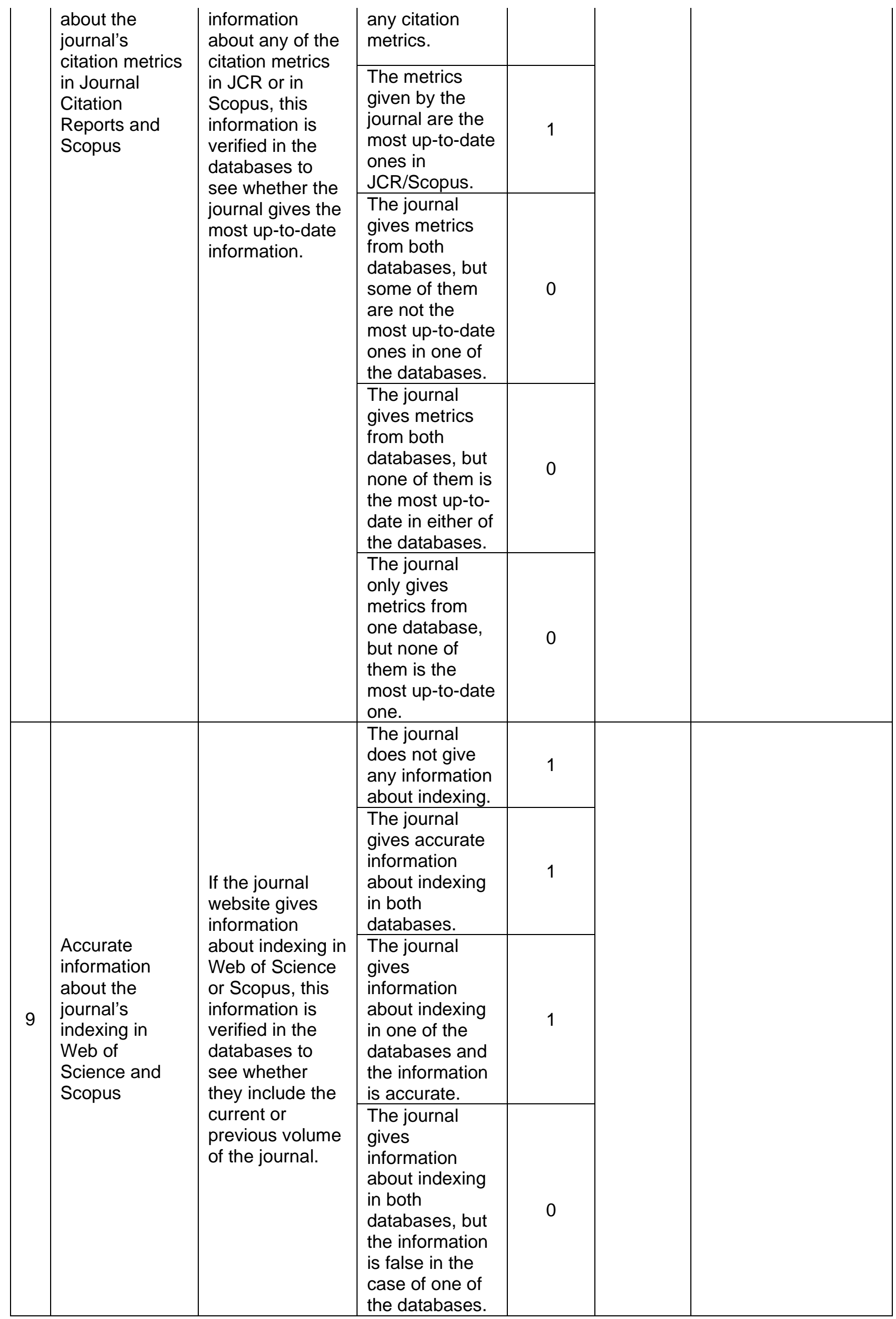




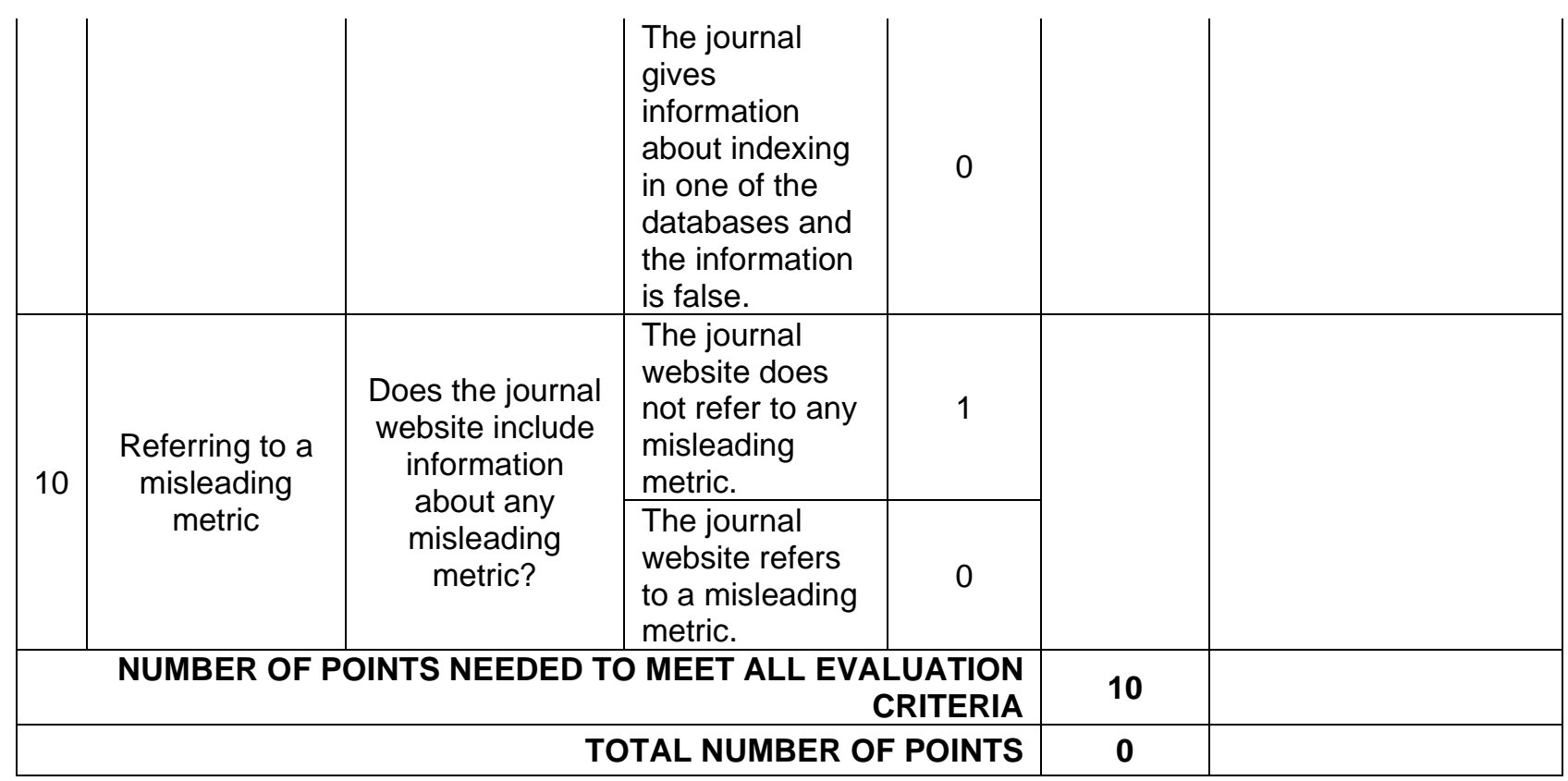

Table 2 - Currently evaluated criteria

\section{Testing of evaluation criteria and methods}

Despite checking only the objectively verifiable criteria now, we continue to critically discuss our evaluation method and test its functionality. First of all, we organised two workshops in September and November 2018 related to defining the criteria (the first one for 14 librarians from European universities and the second one for 5 librarians from Czech universities). The aim of these workshops was to ascertain the views of the participating librarians on this topic.

During the brainstorming, both groups defined 122 criteria in the following categories: archiving, APCs, copyright, governing body, indexation, peer-review, publication ethics and publisher policy. Then the three most important criteria in each category got three points, three more important criteria received two points and three important criteria one point. We calculated a score for each criterion in the following way: the sum of points awarded to a criterion was divided by a maximum possible points for that criterion (e.g. a criterion got a score of 71.4 from the European librarians for 30 points awarded from 42 possible points while the Czech librarians rated this score with 100 for 15 points awarded from the 15 possible points). The group of Czech librarians gave at least one point to 49 criteria out of the total 122 criteria, and the group of foreign librarians to 90 criteria. There were only 26 criteria that received one or more point by both groups of librarians, and nine criteria were given zero points by both groups (Table 3). However, these criteria included also the questionable ones such as the already mentioned archiving of full texts, length (schedule) of the review process, contact information, international editorial board, and licence terms. The preference of questionable criteria and the frequent appearance of significant differences in scores of the individual criteria confirmed the problem of finding a standardised approach to journal evaluation.

\begin{tabular}{|l|l|r|r|}
\hline \multicolumn{1}{|c|}{ Area } & \multicolumn{1}{|c|}{ Criterion } & $\begin{array}{c}\text { Scores } \\
\text { according } \\
\text { to } \\
\text { European } \\
\text { librarians }\end{array}$ & $\begin{array}{c}\text { Scores } \\
\text { according } \\
\text { to Czech } \\
\text { librarians }\end{array}$ \\
\hline Indexation & $\begin{array}{l}\text { Clear and accurate information about indexing } \\
\text { databases }\end{array}$ & 71.4 & 100.0 \\
\hline Article processing charges & $\begin{array}{l}\text { Unambiguous determination of article processing } \\
\text { charges }\end{array}$ & 71.4 & 80.0 \\
\hline Governing body & Complete affiliation of editorial board members & 71.4 & 80.0 \\
\hline Archiving & $\begin{array}{l}\text { Long-term archiving with a guarantee of future } \\
\text { accessibility/traceability of previous issues }\end{array}$ & 64.3 & 100.0 \\
\hline $\begin{array}{l}\text { Peer-review/Publisher } \\
\text { policy }\end{array}$ & Description of the review process & 64.3 & 75.0 \\
\hline
\end{tabular}




\begin{tabular}{|c|c|c|c|}
\hline $\begin{array}{l}\text { Governing body/Publisher } \\
\text { policy }\end{array}$ & $\begin{array}{l}\text { Contact details (not limited to a web form, address) } \\
\text { / contact details for authors }\end{array}$ & 59.5 & 50.0 \\
\hline Indexation & $\begin{array}{l}\text { No questionable metrics (such as Index } \\
\text { Copernicus) }\end{array}$ & 57.1 & 93.3 \\
\hline Governing body & $\begin{array}{l}\text { Existence of editorial board members (easily } \\
\text { traceable) \& the members are aware of their } \\
\text { membership }\end{array}$ & 57.1 & 80.0 \\
\hline Publisher policy/Copyright & Information about licence terms & 57.1 & 73.3 \\
\hline Article processing charges & Clearly specified policy for each journal & 50.0 & 93.3 \\
\hline Archiving & $\begin{array}{l}\text { Does the journal have a clearly specified archiving } \\
\text { policy? }\end{array}$ & 50.0 & 26.7 \\
\hline Indexation & $\begin{array}{l}\text { The field of the journal corresponds to the field of } \\
\text { the database }\end{array}$ & 50.0 & 13.3 \\
\hline Archiving/Copyright & Information about archiving options (SHERPA) & 48.8 & 40.0 \\
\hline Publication ethics & Instructions for authors are available & 47.6 & 40.0 \\
\hline Archiving & Information about persistent identifiers (URI/DOI) & 45.2 & 80.0 \\
\hline Peer review & $\begin{array}{l}\text { Overview of the aspects subject to review and } \\
\text { evaluation }\end{array}$ & 45.2 & 26.7 \\
\hline Peer review & Schedule of the review process & 40.5 & 70.0 \\
\hline Governing body & International editorial board & 38.1 & 73.3 \\
\hline $\begin{array}{l}\text { Publication } \\
\text { ethics/Publisher policy }\end{array}$ & Compliance with ethical standards & 35.7 & 80.0 \\
\hline Archiving & $\begin{array}{l}\text { Membership in a respected organisation (such as } \\
\text { CLOCKSS) }\end{array}$ & 35.7 & 46.7 \\
\hline Publisher policy & Access policy (OA, hybrid, subscription) & 26.2 & 80.0 \\
\hline Article processing charges & Information about the payment method & 26.2 & 66.7 \\
\hline Publication ethics & Anti-plagiarism system or software & 26.2 & 60.0 \\
\hline Archiving & $\begin{array}{l}\text { Universal formatting of data and full texts for } \\
\text { archiving }\end{array}$ & 23.8 & 13.3 \\
\hline Copyright & Creative Commons & 21.4 & 100.0 \\
\hline Article processing charges & Information about discounts & 19.0 & 13.3 \\
\hline Copyright & GNU software licence & & \\
\hline Copyright & $\begin{array}{l}\text { The web homepage includes the Open Access } \\
\text { licence terms }\end{array}$ & & \\
\hline Indexation & Current metrics values & & \\
\hline Peer review & $\begin{array}{l}\text { The journal requires the research/results to be } \\
\text { topical }\end{array}$ & & \\
\hline Peer review & The journal requires the text to be original & & \\
\hline Peer review & It is forbidden to require journal self-citations & & \\
\hline Publication ethics & $\begin{array}{l}\text { The journal states that it forbids "salami publishing" } \\
\text { and other transgressions }\end{array}$ & & \\
\hline Publication ethics & Citation rules are stated & & \\
\hline Publication ethics & $\begin{array}{l}\text { It is forbidden to submit articles to several journals } \\
\text { at the same time }\end{array}$ & & \\
\hline
\end{tabular}

Table 3 - Overview of criteria selected as important and unimportant by librarians at both workshops

Besides defining the criteria, we carried out a comparative test. Our three evaluation tables were applied to a group of journals in order to determine possible changes in evaluation results. For the pilot test, we used 12 journals, which we evaluated between June 2018 and January 2019 for our users according to ET19 (or rather 11 journals, because two of our users asked us independently of each other to evaluate the journal Neuropsychiatry; see Sheet 3 in the Appendix). Because ET19 includes all 10 criteria from ET10R, we automatically obtained evaluation results according to both tables. Therefore, only the newly-added criterion misleading metrics needed to be verified additionally to get results according to ET10M. In order to display the 
journals' websites in the state closest to the date of the original evaluation, we used the Internet Archive (https://web.archive.org/).

The results (Sheet 3 in Appendix) showed that while none of the journals met all criteria from ET19, the journal Crystals complied with all criteria from ET10R and the journals Crystals, Metals and Materials met all criteria from ET10M. The differences in results were clearly caused by eliminating questionable criteria. The disputability of the length of the review process was proven obvious by comparing the results gained by evaluating journals according to ET10R and ET10M. If we set the boundary to 14 days according to the median time from submission to acceptance for all articles in JAMA (American Medical Association, c2019) instead of six weeks according to earlier surveys (Nguyen et al., 2015; Wicherts, 2016), then also Metals and Materials would meet all criteria when using ET10R. After all, the problematic nature of this criterion was already indicated by our previous study (Kratochvíl et al., 2019), which revealed that the review process was shorter than 5 weeks in $28 \%$ of the 259 biomedical journals in OA mode that were analysed. These journals which did not state the dates of review process and whose review process was shorter than 4 weeks also included titles from traditional publishing houses such as BioMed Central, Elsevier, Nature Publishing Group, Oxford University Press, and Wiley. The results of this test confirmed that excluding the criterion length of the review process from evaluated criteria was a correct decision. When processing the results, it also became apparent that despite checking objectively verifiable criteria, the result may nevertheless be subjective. As we provided our service, we encountered various questionable situations with other criteria as well.

In the case of affiliation of editorial board members, the question arises of whether the affiliation must include the name of the institution as well as a city/country, or if only one of these details suffices. A number of journals provide only a city or town, such as New England Journal of Medicine (Massachusetts Medical Society, c2019) or only an institution, e.g. CA: A Cancer Journal for Clinicians (John Wiley \& Sons, c2019) or even none of these details, e.g. The Lancet (Elsevier, c2019). Under these circumstances, not only does it seem dubious to award zero points to journals with incomplete information about affiliation in our test (e.g. to the journal Progress in Nutrition which provides only institutions for editorial-board members) but also the justifiability of this criterion can be doubted. If this criterion is kept, numerous journals would not meet the criteria from our ET10M but also from other evaluation methods described above (Dadkhah \& Bianciardi, 2016; Rele et al., 2017; Teixeira da Silva, 2013). Nevertheless, we consider this criterion important because it enables readers to identify members of the editorial board unambiguously and it gives them an idea about the professional background of the journal. Complete affiliation is important so that various institutions with the same name can be told apart (e.g. a Heidelberg University exists both in Germany and in Ohio, USA, and a University of St. Thomas in St. Paul, Minnesota and in Houston, Texas). Besides this, the requirement to provide a complete affiliation is one of the principles of COPE, which states that "journals shall provide the full names and affiliations [...]" (COPE et al., 2018).

After the pilot test, we decided to run further tests concurrently. In the first test, we used the findings about 259 biomedical OA journals in JCR from our preceding study (Kratochvíl et al., 2019), reduced the original 14 criteria to 10 according to ET10M and counted the number of journals which meet all the criteria. While only 4 journals met all 14 criteria from the original study, 78 journals complied with our current 10 criteria - that is 74 journals more than before. More than half (45) of them belong to the publisher BioMed Central and others to local publishers and occasionally to traditional publishing houses such as Taylor \& Francis (2 journals) or Oxford University Press and Wiley (one journal each). However, also among titles from traditional publishers appeared those which violated at least on criterion - Springer (4 journals), Elsevier and Wiley (both 3 journals), Oxford University Press and Taylor \& Francis (both 2 journals), Nature Publishing Group and BioMed Central (both 1 journals). The test thus revealed a limitation of ET10 which consists in the risk of assessing a journal from a traditional publisher as a problematic one. Naturally, it is the responsibility of each publisher to prevent this risk by complying with all COPE requirements (COPE et al., 2018). However, these requirements are just unenforceable recommendations, and also one cannot disregard common practice in narrowly specialised fields in which researchers know each other and are able to identify members of an editorial board without complete affiliation.

In the second test, we used the dataset of 259 biomedical OA journals for an attempt to create a regression model which would help users to determine the level of risk according to how much a journal complies with individual criteria. We chose a mining analysis for this test and applied nonparametric classification and regression trees (C\&RT) (Kanungo, Sharma, \& Pain, 2014) with the level of risk as the dependent variable. The C\&RT classifies the individual instances based on a simple criterion. All homogeneous instances are in precisely one leaf of the tree, while all the other instances are in a different leaf in such a way that the most homogeneous ones are together. The C\&RT algorithm creates several classification trees and continuously calculates the importance of the individual variables, so that the $\mathrm{n}$-th observation is classified in the correct 
category in all trees. The result is an ordered list of variables that most often affect the correct classification, even though they might not always be present in the tree structure. This list is included in Table 4.

During this test, we applied criteria from ET10M to the dataset. To see whether the results would change when using weighted and unweighted scores paired with different scoring methods, we prepared three sets of data: the original weighted scores on the scale 2-1-0 from our preceding study (Kratochvíl et al., 2019), other weighted scores on the scale 4-2-0, and unweighted scores on the scale 1-0 (i.e. the options originally awarded 2 points and 1 point were both awarded 1 point). According to the final score, the journals in each set with scores 2-1-0 and 4-2-0 were divided into four quartiles based on the level of risk (high, heightened, low, zero) while journals in the set with scores 1-0 were divided into risky and risk-free.

The results showed that the most commonly violated criteria are affiliations of editorial board members and APCs (Table 4). The criterion "True information on metrics from WoS/Scopus" is not included in the list of criteria since there was no data variability for this criterion and so it had no impact on the calculations. Figure 1 is an example of one of the C\&RT, specifically of the variant with scores 1-0 and the route beginning Affiliations of editorial board members $\rightarrow$ Unambiguous determination of article processing charges $\rightarrow$ Proclamation of dubious metrics/databases. In the variant 2-1-0 the route began with Unambiguous determination of article processing charges $\rightarrow$ Affiliations of editorial board members $\rightarrow$ Description of peer review and in the 4-2-0 variant with Unambiguous determination of article processing charges $\rightarrow$ Affiliations of editorial board members $\rightarrow$ Journal states its ISSN on its website. These findings revealed that affiliation and APCs are the criteria which one needs to be particularly careful about when assessing a journal, but they also showed that our regression model may generate a journal assessment that is doubtful.

\begin{tabular}{|l|c|c|c|}
\hline Criterion & $\mathbf{4 - 2 - 0}$ & $\mathbf{2 - 1 - 0}$ & $\mathbf{1 - 0}$ \\
\hline Affiliation of editorial board members & 1 & 1 & 4 \\
\hline Unambiguous determination of article processing charges & 2 & 2 & 1 \\
\hline Journal states its ISSN on its website & 3 & 5 & 6 \\
\hline Statement of indexing in WoS/Scopus & 4 & 4 & 5 \\
\hline Description of peer review & 5 & 3 & 2 \\
\hline Proclamation of dubious metrics/databases & 6 & 5 & 3 \\
\hline Editor-in-chief & 7 & 6 & 7 \\
\hline Accessibility of full texts & 8 & 8 & 9 \\
\hline Publisher & 9 & 7 & 8 \\
\hline True information on metrics from WoS/Scopus & - & - & - \\
\hline
\end{tabular}

Table 4 - The criteria most often violated by biomedical OA journals in JCR $(1=$ most often violated, $9=$ least often violated) 
Tree 3 graph for Results

Num. of non-terminal nodes: 4 , Num. of terminal nodes: 5

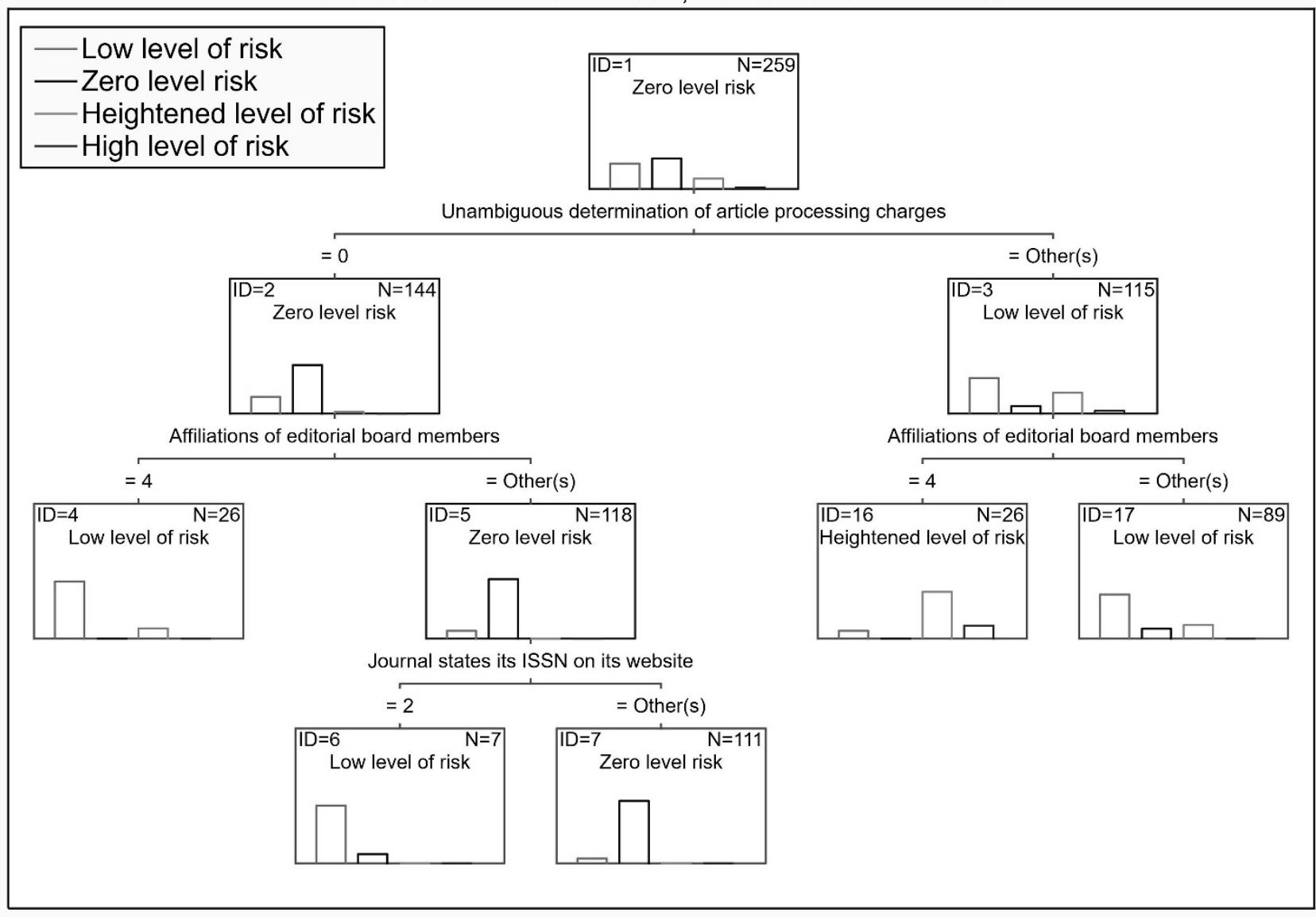

Figure 1 - Example of a C\&RT with the criteria weighted on a 4-2-0 scale.

\section{Proposed solution}

An analysis of the present methods for evaluation, including our own, revealed that mere monitoring of formal criteria is not sufficient and that an otherwise objectively verifiable criterion may be disputed and is dependent on the truthfulness of the information on the websites of journals. The existing studies as well as our discussions with colleagues from the Czech Republic and abroad showed that agreeing on a standardised evaluation method is problematic, if not impossible. Moreover, all this showed that checking the formal criteria is just the first of three essential steps for journal evaluation.

In one of our tests, the journals Crystals, Metals, and Materials from the publisher MDPI complied with the most criteria from ET10R and ET10M, and yet this publisher has appeared on Beall's List in the past (MDPI, 2019) and was accused of exerting pressure on the editorial board of one of its journals Nutrients to accept and publish articles of lower quality (de Vrieze, 2018; MDPI, 2018). In another test, journals from traditional publishing houses such as Elsevier, Springer and Wiley did not meet some of the criteria. Both these cases demonstrate that de facto any evaluation method based merely on checking formal criteria may fail. In addition, during the time we provided our service, it became apparent that despite the effort to evaluate objectively, the subjective view of the evaluator may always influence the result.

For example, when evaluating the Journal of Physical Education and Sport (University of Pitesti, 2018) we hesitated whether the information "open peer review" without any further details (e.g. the number of reviewers) suffices to comply with the criterion description of the review process. Another example is how to decide when assessing the criterion citation metrics when the journal Oncotarget truly claims exclusion from JCR but at the same time encourages readers to calculate the current impact factor by themselves. Another question that arose is whether the criterion indexation in Web of Science is complied with when the journal Parkinson's Disease (Hindawi, [c2019]) claims to be indexed there but the last articles in the database come from 2017. For some the information "open peer review" may be sufficient while for others not. Or in the case of Parkinson's Disease, some may understand this criterion as indexation of articles from the current year while 
others may consider indexation of any article sufficient. In other words, despite objectively determined criteria, the evaluation according to them may be subjective.

The second step during journal evaluation must be an analysis of the journal's content focused mainly on its professional quality rather than on bad grammar or spelling as commonly associated with predatory journals (Edie \& Conklin, 2019; Frandsen, 2019a). Many authors have published in untrustworthy journals because they did not assess its professional quality (Frandsen, 2019b) despite the fact that one can use one of the checklists which help to focus on the quality of text processing besides their professional knowledge (Andrew, Traynor, \& Iverson, 2015; Coughlan, Cronin, \& Ryan, 2007; Nadelson \& Nadelson, 2014; Ryan, Coughlan, \& Cronin, 2007). Although the checklists were recommended in journals focused on nursing, some of them can be used in other fields as well because they are intended for case reports and qualitative or quantitative reports. For example, the Joanna Briggs Institute ([c2019]) has created critical appraisal tools for various types of studies with questions checking comprehensibility, attention to detail, objectivity, and verifiability of the research results. Each of these questions is complemented with an explanation of what specifically the question is aiming at in the article. A similar aid are the checklists from the Critical Appraisal Skills Programme (CASP, c2018) containing questions about the clarity of aims and results of the research, the suitability of the chosen research method and the results collection as well as compliance with ethical principles of research. These tools help authors to assess the quality of the content of randomly chosen articles not only based on their specialisation but also with the help of a standardised method. In this way authors can get an idea about the quality of editorial work and the journal's requirements for the professional quality of the published articles.

Naturally, even these tools for content analysis of articles have their limitations. However, when even experienced researchers publish in untrustworthy journals (Bagues et al., 2017), the subject of the content analysis may be a high-quality article which, despite being published in an untrustworthy journal, meets all the criteria of the checklist and whose professional level is adequate. On the other hand, an inexperienced author may not be able to reliably assess the quality of research results (Bagues, Sylos-Labini, \& Zinovyeva, 2019).

Thus, this is why a third step is necessary during which one needs to gain information about the journal's background and operation. In the case of journals with open peer review, it is necessary to read some peer reviews and the communication between the reviewers and the editor, as this reveals the most about the review process and the editor's reasons for accepting an article ('Transparent peer review and open data at Communications Biology', 2019). In other cases one must draw information about the journal from secondary sources. These sources may include platforms such as ResearchGate, Academia.edu, Retractionwatch.com, and Retractiondatabase.org, where researchers share their experience with publishing. Naturally, information gained on these platforms needs to be assessed critically. For example, one cannot conclude that the whole journal is untrustworthy after seeing one article with forged or otherwise manipulated results. Instead, one should check whether, for example, the editorial board of the journal properly retracted the article afterwards. Or in the case that one uses platforms such as ResearchGate, one must pay attention to whether the discussants support their claims with evidence (Jeng, DesAutels, He, \& Li, 2017; Li, He, \& Zhang, 2016).

Indexation of a journal in JCR and Scopus may also indicate how reliable the journal is, because if a journal fails to meet their evaluation criteria or exhibits non-standard citation practices, the journal is excluded from the interface accessible to users (Elsevier, 2017; Web of Science Group, 2019). Therefore, users should be interested in the reason why the indexation of a journal was interrupted or terminated. Such reasons are briefly described by JCR in the list of title suppressions (Clarivate Analytics, 2018) and by Scopus in Discontinued Sources (Elsevier, 2019). If necessary, one can try to reconstruct their evaluation approach. When evaluating a journal indexed in JCR, one needs to focus on possible non-standard citation practices of the journal (a significant increase or fall in the number of citations, self-citations, and articles, majority of citations from a small group of journals) as well as on compliance with 28 criteria from JCR (Web of Science Group, c2019, 2019). Journals indexed in Scopus should be checked within their field of expertise for the self-citation rate, total citation rate, CiteScore, number of articles, number of full-text clicks and abstract usage on Scopus.com (Elsevier, 2017).

Unfortunately, also this type of verification has its limits. For example, JCR includes the criterion affiliation the result of which - as shown by the example of New England Journal of Medicine, CA: A Cancer Journal for Clinicians and The Lancet above - may be subjective and disputable. Scopus checks in the criterion number of articles whether "the journal produced half, or less, the number of articles, when compared to peer journals in its subject field", but does not explain why it should be half and not a different number. Moreover, this criterion ignores the fact that due to the varying periodicity of journals, the number of articles published may differ as well.

Despite its limits, the approach described above in combination with a check of formal criteria, the journal's background and content analysis provides a more effective tool for avoiding the risk of publishing in an untrustworthy journal than the current methods focused merely on assessment of formal criteria. In addition, it 
can be expected that our approach will require closer cooperation between the author and the librarian who can discuss their findings about the journal and thus eliminate the limits of individual evaluation steps described above.

\section{Conclusion}

The analysis of earlier published evaluation methods together with our own approach confirmed that there is a problem with standardisation of the evaluation process and that one must not rely merely on compliance with formal criteria when evaluating a journal (Frandsen, 2019a). As further discussion about journal evaluation method is indispensable, it will be useful to carry out a survey among authors regarding their view on what represents good practice in scientific publishing. This may help detect phenomena which have been overlooked when evaluating journals. It has been confirmed that a close cooperation between authors and librarians is necessary (Frandsen, 2019a) as well as the duty of libraries to continue with raising awareness about untrustworthy journals and helping authors with criteria assessment and detecting possible peculiarities connected with the journal.

\section{References}

American Medical Association. (c2019). For authors. Retrieved 24 March 2019, from https://jamanetwork.com/journals/jama/pages/for-authors\#fa-why-publish

Anderson, R. (2017, July 25). Cabell's new predatory journal blacklist: A review. Retrieved 24 March 2019 , from https://scholarlykitchen.sspnet.org/2017/07/25/cabells-new-predatory-journal-blacklist-review/

Andrew, C., Traynor, V., \& Iverson, D. (2015). An integrative review: Understanding driving retirement decisions for individuals living with a dementia. Journal of Advanced Nursing, 71(12), 2728-2740. https://doi.org/10.1111/jan.12727

Ayeni, P. O., \& Adetoro, N. (2017). Growth of predatory open access journals: Implication for quality assurance in library and information science research. Library Hi Tech News, 34(1), 17-22. https://doi.org/10.1108/LHTN-10-2016-0046

Bagues, M. F., Sylos Labini, M., \& Zinovyeva, N. (2017). A walk on the wild side: An investigation into the quantity and quality of 'predatory' publications in Italian academia. Retrieved 24 March 2019, from http://www.lem.sssup.it/WPLem/files/2017-01.pdf

Bagues, M. F., Sylos-Labini, M., \& Zinovyeva, N. (2019). A walk on the wild side: 'Predatory' journals and information asymmetries in scientific evaluations. Research Policy, 48(2), 462-477. https://doi.org/10.1016/j.respol.2018.04.013

Baruch, Y., Ghobadian, A., \& Özbilgin, M. (2013). Open Access - the wrong response to a complex question: The case of the Finch report: Open Access. British Journal of Management, 24(2), 147155. https://doi.org/10.1111/1467-8551.12016

Beall, J. (2010). 'Predatory' Open-Access scholarly publishers. The Charleston Advisor, 11(4), $10-17$. https://www.ingentaconnect.com/content/charleston/chadv/2010/00000011/00000004/art00005\#

Beall, J. (2015). Criteria for determining predatory Open-Access Publishers (3rd ed.). Retrieved 24 March 2019, from https://beallslist.weebly.com/uploads/3/0/9/5/30958339/criteria-2015.pdf

Beall, J. (2016). Dangerous predatory publishers threaten medical research. Journal of Korean Medical Science, 31(10), 1511-1513. https://doi.org/10.3346/jkms.2016.31.10.1511

Beall, J. (2017, January 11). Misleading metrics. Retrieved 18 October 2019, from https://web.archive.org/web/20170111172311/https://scholarlyoa.com/other-pages/misleadingmetrics/

Berger, M. (2017). Everything you ever wanted to know about predatory publishing but were afraid to ask. ACRL 2017. Presented at the ARCL 2017, Baltimore, Maryland, March 22-25, 2017, Baltimore. Retrieved 18 October 2019, from https://academicworks.cuny.edu/ny_pubs/141

Bisaccio, M. (2018). Cabells' journal whitelist and blacklist: Intelligent data for informed journal evaluations. Learned Publishing, 31(3), 243-248. https://doi.org/10.1002/leap.1164

Bloudoff-Indelicato, M. (2015). Backlash after Frontiers journals added to list of questionable publishers. Nature, 526(7575), 613. https://doi.org/10.1038/526613f

Bowman, M. A., Saultz, J. W., \& Phillips, W. R. (2018). Beware of predatory journals: A caution from editors of three Family Medicine Journals. Journal of the American Board of Family Medicine, 31(5), 671676. https://doi.org/10.3122/jabfm.2018.05.180197

CASP. (c2018). CASP checklists. Retrieved 12 November 2019, from https://casp-uk.net/casp-toolschecklists/

Centro ASK. (2011). PEER Economics Report. Retrieved 24 March 2019, from http://www.peerproject.eu/fileadmin/media/reports/PEER_Economics_Report.pdf 
Clarivate Analytics. (2018). Title suppressions. Retrieved 4 November 2019, from http://help.incites.clarivate.com/incitesLiveJCR/JCRGroup/titleSuppressions.html

Clements, J. C., Daigle, R. M., \& Froehlich, H. E. (2018). Predator in the pool? A quantitative evaluation of non-indexed Open Access journals in aquaculture research. Frontiers in Marine Science, 5(March), 106. https://doi.org/10.3389/fmars.2018.00106

CLSJEP. ([c2019]). Aims and scope. Retrieved 17 October 2019, from http://www.cspatologie.cz/enprofil.php

Cobey, K. D., Lalu, M. M., Skidmore, B., Ahmadzai, N., Grudniewicz, A., \& Moher, D. (2018). What is a predatory journal? A scoping review. F1000Research, 7. https://doi.org/10.12688/f1000research.15256.2

COPE, OASPA, DOAJ, \& WAME. (2018). Principles of transparency and best practice in scholarly publishing. Retrieved 24 March 2019, from

https://publicationethics.org/files/Principles_of_Transparency_and_Best_Practice_in_Scholarly_Publi shingv3.pdf

Cortegiani, A., Sanfilippo, F., Tramarin, J., \& Giarratano, A. (2019). Predatory open-access publishing in critical care medicine. Journal of Critical Care, 50, 247-249. https://doi.org/10.1016/j.jcrc.2018.12.016

Coughlan, M., Cronin, P., \& Ryan, F. (2007). Step-by-step guide to critiquing research. Part 1: Quantitative research. British Journal of Nursing (Mark Allen Publishing), 16(11), 658-663. https://doi.org/10.12968/bjon.2007.16.11.23681

Crawford, W. (2014). Ethics and access 1: The sad case of Jeffrey Beall. Cites \& Insights, 14(4). https://citesandinsights.info/civ14i4.pdf

Dadkhah, M., \& Bianciardi, G. (2016). Ranking predatory journals: Solve the problem instead of removing It!. Advanced Pharmaceutical Bulletin, 6(1), 1-4. https://doi.org/10.15171/apb.2016.001

Darbyshire, P., McKenna, L., Lee, S. F., \& East, C. E. (2017). Taking a stand against predatory publishers. Journal of Advanced Nursing, 73(7), 1535-1537. https://doi.org/10.1111/jan.13004

de Vrieze, J. (2018, September 4). Open-access journal editors resign after alleged pressure to publish mediocre papers. Retrieved 22 October 2019, from

https://www.sciencemag.org/news/2018/09/open-access-editors-resign-after-alleged-pressurepublish-mediocre-papers

Drayton, N. (2019, April 3). Court rules in FTC's favor against predatory academic publisher OMICS Group; Imposes \$50.1 million judgment against defendants that made false claims and hid publishing fees. Retrieved 15 October 2019, from https://www.ftc.gov/news-events/press-releases/2019/04/courtrules-ftcs-favor-against-predatory-academic-publisher-omics

Edie, A. H., \& Conklin, J. L. (2019). Avoiding predatory journals: Quick peer review processes too good to be true. Nursing Forum, 54(3), 336-339. https://doi.org/10.1111/nuf.12333

Elsevier. (c2019). People at The Lancet. Retrieved 22 October 2019, from https://www.thelancet.com/lancetpeople

Elsevier. (2017). Scopus: Content coverage guide. Retrieved 24 March 2019, from https://www.elsevier.com/_data/assets/pdf_file/0007/69451/0597-Scopus-Content-CoverageGuide-US-LETTER-v4-HI-singles-no-ticks.pdf

Elsevier. (2019). Stay abreast of the research happening in your area. Retrieved 4 November 2019, from https://www.elsevier.com/solutions/scopus/how-scopus-works/content

Emerald Publishing. (c2019). The Electronic Library editorial team. Retrieved 18 March 2019, from http://emeraldgrouppublishing.com/products/journals/editorial_team.htm?id=el

Erfanmanesh, M., \& Pourhossein, R. (2017). Publishing in predatory Ōpen Access journals: A case of Iran. Publishing Research Quarterly, 33(4), 433-444. https://doi.org/10.1007/s12109-017-9547-y

Eriksson, S., \& Helgesson, G. (2018). Time to stop talking about 'predatory journals'. Learned Publishing, 31(2), 181-183. https://doi.org/10.1002/leap.1135

European Commission. (2017). H2020 programme: Guidelines to the rules on Open Access to scientific publications and Open Access to research data in Horizon 2020 (version 3.2). Retrieved 24 March 2019, from

http://ec.europa.eu/research/participants/data/ref/h2020/grants_manual/hi/oa_pilot/h2020-hi-oa-pilotguide_en.pdf

Eve, M. P., \& Priego, E. (2017). Who is actually harmed by predatory publishers? TripleC: Communication, Capitalism \& Critique. Open Access Journal for a Global Sustainable Information Society, 15(2), 755-770. https://doi.org/10.31269/triplec.v15i2.867

Eysenbach, G. (2008, March 8). Black sheep among Open Access Journals and Publishers. Retrieved 24 March 2019, from http://gunther-eysenbach.blogspot.com/2008/03/black-sheep-among-openaccess-journals.html

Frandsen, T. F. (2019a). How can a questionable journal be identified: Frameworks and checklists. Learned Publishing, 32(3), 221-226. https://doi.org/10.1002/leap.1230 
Frandsen, T. F. (2019b). Why do researchers decide to publish in questionable journals? A review of the literature: Why authors publish in questionable journals. Learned Publishing, 32(1), 57-62. https://doi.org/10.1002/leap.1214

Gargouri, Y., Hajjem, C., Larivière, V., Gingras, Y., Carr, L., Brody, T., \& Harnad, S. (2010). Self-Selected or Mandated, Open Access Increases Citation Impact for Higher Quality Research. PLoS ONE, 5(10), e13636. https://doi.org/10.1371/ journal.pone.0013636

Gasparyan, A. Y., Yessirkepov, M., Diyanova, S. N., \& Kitas, G. D. (2015). Publishing ethics and predatory practices: A dilemma for all stakeholders of science communication. Journal of Korean Medical Science, 30(8), 1010-1016. https://doi.org/10.3346/jkms.2015.30.8.1010

Global Society for Scientific Research. (c2014). Welcome to JIFACTOR. Retrieved 12 May 2019, from http://jifactor.org/

Gonzalez, J., Bridgeman, M. B., \& Hermes-DeSantis, E. R. (2018). Differentiating predatory scholarship: Best practices in scholarly publication. The International Journal of Pharmacy Practice, 26(1), 73-76. https://doi.org/10.1111/ijpp.12380

Hansoti, B., Langdorf, M. I., \& Murphy, L. S. (2016). Discriminating between legitimate and predatory Open Access journals: Report from the International federation for emergency medicine research committee. Western Journal of Emergency Medicine, 17(5), 497-507. https://doi.org/10.5811/westjem.2016.7.30328

Harnad, S. (2008, July 15). The Dot-gold rush for Open Access. Retrieved 24 March 2019, from http://openaccess.eprints.org/index.php?/archives/432-The-Dot-Gold-Rush-for-Open-Access.html

Harzing, A.-W., \& Adler, N. J. (2016). Disseminating knowledge: From potential to reality-New OpenAccess journals collide with convention. Academy of Management Learning \& Education, 15(1), 140-156. https://doi.org/10.5465/amle.2013.0373

Hill, T. (2015). Identifying legitimate open access journals: Some suggestions from a publisher. Learned Publishing, 28(1), 59-62. https://doi.org/10.1087/20150109

Hindawi. ([c2019]). Abstracting and indexing. Retrieved 12 November 2019, from https://www.hindawi.com/journals/pd/ai/

Huffman, J. (2017). Publisher package and Open Access journals: Are any of them predatory? The Serials Librarian, 73(3-4), 248-268. https://doi.org/10.1080/0361526X.2017.1389796

Huisman, J., \& Smits, J. (2017). Duration and quality of the peer review process: The author's perspective. Scientometrics, 113(1), 633-650. https://doi.org/10.1007/s11192-017-2310-5

Institute for Information Resources. (2017, c2010). Evaluation method. Retrieved 12 May 2019, from http://globalimpactfactor.com/evaluatiion-method/

Jeng, W., DesAutels, S., He, D., \& Li, L. (2017). Information exchange on an academic social networking site: A multidiscipline comparison on researchgate Q\&A. Journal of the Association for Information Science and Technology, 68(3), 638-652. https://doi.org/10.1002/asi.23692

Joanna Briggs Institute. ([c2019]). Critical appraisal tools. Retrieved 12 November 2019, from https://joannabriggs.org/critical_appraisal_tools

John Wiley \& Sons. (c2019). CA: A Cancer Journal for Clinicians: Editorial board. Retrieved 22 October 2019, from https://onlinelibrary.wiley.com/page/journal/15424863/homepage/editorialboard.html

Kahn, M. (2014). Sharing your scholarship while avoiding the predators: Guidelines for medical physicists interested in open access publishing. Medical Physics, 41(7), 070401. https://doi.org/10.1118/1.4883836

Kanungo, D. P., Sharma, S., \& Pain, A. (2014). Artificial neural network (ANN) and Regression tree (CART) applications for the indirect estimation of unsaturated soil shear strength parameters. Frontiers of Earth Science, 8(3), 439-456. https://doi.org/10.1007/s11707-014-0416-0

Kratochvíl, J., Plch, L., \& Koritáková, E. (2019). Compliance with transparency and best practice in scholarly publishing in biomedical Open Access journals indexed in Journal Citation Reports. Vnitřní Lékařství, 65(5), 338-347. http://is.muni.cz/repo/1527916/clanek.pdf

Kumar, P., \& Saxena, D. (2016). Pandemic of publications and predatory journals: Another nail in the coffin of academics. Indian Journal of Community Medicine, 41(3), 169-171. https://doi.org/10.4103/09700218.183586

Li, L., He, D., \& Zhang, C. (2016). Evaluating academic answer quality: A pilot study on ResearchGate Q\&A. In F. F.-H. Nah \& C.-H. Tan (Eds.), HCl in Business, Government, and Organizations: ECommerce and Innovation (pp. 61-71). Switzerland: Springer. https://doi.org/10.1007/978-3-319-39396-4_6

Lucia, D. (2017, June 26). Science's fake journal epidemic. Retrieved 24 March 2019, from http://blogs.nature.com/naturejobs/2017/06/26/sciences-fake-journal-epidemic/

Macháček, V., \& Srholec, M. (2017). Predatory journals in Scopus. Retrieved 24 March 2019, from https://idea-en.cerge-

ei.cz/files/IDEA_Study_2_2017_Predatory_journals_in_Scopus/files/downloads/IDEA_Study_2_201 7_Predatory_journals_in_Scopus.pdf

Massachusetts Medical Society. (c2019). Editors and publishers. Retrieved 22 October 2019, from https://www.nejm.org/about-nejm/editors-and-publishers 
Masten, Y. B., \& Ashcraft, A. S. (2016). The dark side of dissemination: Traditional and Open Access versus predatory journals. Nursing Education Perspectives, 37(5), 275-277. https://doi.org/10.1097/01.NEP.0000000000000064

McCann, T. V., \& Polacsek, M. (2018). False gold: Safely navigating open access publishing to avoid predatory publishers and journals. Journal of Advanced Nursing, 74(4), 809-817. https://doi.org/10.1111/jan.13483

McGlinchey, N. (2017, March 23). When should reviewers receive reminders? Retrieved 4 April 2019, from https://www.wiley.com/network/researchers/being-a-peer-reviewer/when-should-reviewers-receivereminders

MDPI. (2018, September 7). MDPI's comment on Science article. MDPI. Retrieved 8 February 2020, from https://www.mdpi.com/about/announcements/1389

MDPI. (2019, May 8). Update: Response to Mr. Jeffrey Beall's repeated attacks on MDPI. Retrieved 22 October 2019, from https://www.mdpi.com/about/announcements/534

Mongeon, P., \& Paul-Hus, A. (2016). The journal coverage of Web of Science and Scopus: A comparative analysis. Scientometrics, 106(1), 213-228. https://doi.org/10.1007/s11192-015-1765-5

Nadelson, S., \& Nadelson, L. S. (2014). Evidence-Based Practice Article Reviews Using CASP Tools: A Method for Teaching EBP. Worldviews on Evidence-Based Nursing, 11(5), 344-346. https://doi.org/10.1111/wvn.12059

Newland, J. (2016). Predatory publishing. The Nurse Practitioner, 41(8), 13. https://doi.org/10.1097/01.NPR.0000489539.57309.0c

Neylon, C. (2017, January 29). Blacklists are technically infeasible, practically unreliable and unethical. Period. Retrieved 30 March 2019, from http://cameronneylon.net/blog/blacklists-are-technicallyinfeasible-practically-unreliable-and-unethical-period/

Nguyen, V. M., Haddaway, N. R., Gutowsky, L. F. G., Wilson, A. D. M., Gallagher, A. J., Donaldson, M. R., ... Cooke, S. J. (2015). How long is too long in contemporary peer review? Perspectives from authors publishing in conservation biology journals. PloS One, 10(8), e0132557. https://doi.org/10.1371/journal.pone.0132557

Nobes, A. (2017, March 29). Critical thinking in a post-Beall vacuum. Retrieved 20 March 2019, from https://www.researchinformation.info/feature/critical-thinking-post-beall-vacuum

Nolfi, D. A., Lockhart, J. S., \& Myers, C. R. (2015). Predatory publishing: What you don't know can hurt you. Nurse Educator, 40(5), 217-219. https://doi.org/10.1097/NNE.0000000000000179

Olivarez, J. D., Bales, S., Sare, L., \& van Duinkerken, W. (2018). Format aside: Applying Beall's criteria to assess the predatory nature of both $\mathrm{OA}$ and non-OA library and information science journals. College \& Research Libraries, 79(1), 52-67. https://doi.org/10.5860/crl.79.1.52

OMICS International. (c2019). Article processing charges. Retrieved 30 March 2019, from https://www.omicsonline.org/article-processing-charges.php

PIch, L., \& Kratochvíl, J. (2018). Analýza predátorských znaků publikací jako služba Knihovny univerzitního kampusu. Prolnflow, 10(2), 108-129. https://doi.org/10.5817/Proln2018-2-6

PLOS. (2019). Publication fees. Retrieved 30 March 2019, from https://journals.plos.org/plosone/s/publication-fees

Power, $\mathrm{H}$. (2018). Predatory publishing: How to safely navigate the waters of Open Access. The Canadian Journal of Nursing Research, 50(1), 3-8. https://doi.org/10.1177/0844562117748287

Rele, S., Kennedy, M., \& Blas, N. (2017). Journal evaluation tool. LMU Librarian Publications \& Presentations, (40). Retrieved 24 March 2019, from https://digitalcommons.Imu.edu/librarian_pubs/40

Rich, T. S. (2016). Predatory publishing, Open Access, and the costs to academia. PS: Political Science \& Politics, 49(2), 265-267. https://doi.org/10.1017/S1049096516000172

Ross-White, A., Godfrey, C. M., Sears, K. A., \& Wilson, R. (2019). Predatory publications in evidence syntheses. Journal of the Medical Library Association, 107(1), 57-61. https://doi.org/10.5195/jmla.2019.491

Rupp, M., Anastasopoulou, L., Wintermeyer, E., Malhaan, D., El Khassawna, T., \& Heiss, C. (2019). Predatory journals: A major threat in orthopaedic research. International Orthopaedics, 43(3), 509517. https://doi.org/10.1007/s00264-018-4179-1

Ryan, F., Coughlan, M., \& Cronin, P. (2007). Step-by-step guide to critiquing research. Part 2: Qualitative research. British Journal of Nursing (Mark Allen Publishing), 16(12), 738-744. https://doi.org/10.12968/bjon.2007.16.12.23726

Samuel, A. J., \& Aranha, V. P. (2018). Valuable research in fake journals and self-boasting with fake metrics. Journal of Pediatric Neurosciences, 13(4), 517-518. https://doi.org/10.4103/JPN.JPN_66_18

Schmidt, B., Ross-Hellauer, T., van Edig, X., \& Moylan, E. C. (2018). Ten considerations for open peer review. F1000Research, 7, 969. https://doi.org/10.12688/f1000research.15334.1

Shahriari, N., Grant-Kels, J. M., \& Payette, M. J. (2016). Predatory journals: How to recognize and avoid the threat of involvement with these unethical 'publishers'. Journal of the American Academy of Dermatology, 75(3), 658-659. https://doi.org/10.1016/j.jaad.2016.04.056 
Shamseer, L., Moher, D., Maduekwe, O., Turner, L., Barbour, V., Burch, R., ... Shea, B. J. (2017). Potential predatory and legitimate biomedical journals: Can you tell the difference? A cross-sectional comparison. BMC Medicine, 15(1), 28. https://doi.org/10.1186/s12916-017-0785-9

Sharman, A. (2015). Where to publish. The Annals of The Royal College of Surgeons of England, 97(5), 329-332. https://doi.org/10.1308/rcsann.2015.0003

Shen, C., \& Björk, B.-C. (2015). 'Predatory' open access: A longitudinal study of article volumes and market characteristics. BMC Medicine, 13, 230. https://doi.org/10.1186/s12916-015-0469-2

Somoza-Fernández, M., Rodríguez-Gairín, J.-M., \& Urbano, C. (2016). Presence of alleged predatory journals in bibliographic databases: Analysis of Beall's list. El Profesional de La Información, 25(5), 730. https://doi.org/10.3145/epi.2016.sep.03

Sorokowski, P., Kulczycki, E., Sorokowska, A., \& Pisanski, K. (2017). Predatory journals recruit fake editor. Nature, 543(7646), 481-483. https://doi.org/10.1038/543481a

Strinzel, M., Severin, A., Milzow, K., \& Egger, M. (2019). Blacklists and whitelists to tackle predatory publishing: A cross-sectional comparison and thematic analysis. MBio, 10(3), e00411-e00419. https://doi.org/10.1128/mBio.00411-19

Teixeira da Silva, J. A. (2013). Predatory publishing: A quantitative assessment, the predatory score. The Asian and Australasian Journal of Plant Science and Biotechnology, 7(1), 21-34. http://www.globalsciencebooks.info/Online/GSBOnline/images/2013/AAJPSB_7(SI1)/AAJPSB_7(SI1 )21-340.pdf

Teixeira da Silva, J. A., \& Tsigaris, P. (2018). What value do journal whitelists and blacklists have in academia? The Journal of Academic Librarianship, 44(6), 781-792. https://doi.org/10.1016/j.acalib.2018.09.017

Think. Check. Submit. (c2019). Retrieved 24 March 2019, from https://thinkchecksubmit.org/

Tosti, A., \& Maddy, A. J. (2017). Ranking predatory journals in dermatology: Distinguishing the bad from the ugly. International Journal of Dermatology, 56(7), 718-720. https://doi.org/10.1111/ijd.13644

Toutloff, L. (2019, March 20). Cabells Blacklist Criteria v 1.1. Retrieved 12 June 2019, from https://blog.cabells.com/2019/03/20/blacklist-criteria-v1-1/

Transparent peer review and open data at Communications Biology. (2019). Communications Biology, 2, 239. https://doi.org/10.1038/s42003-019-0489-0

Umlauf, M. G., \& Mochizuki, Y. (2018). Predatory publishing and cybercrime targeting academics. International Journal of Nursing Practice, 24 Suppl 1, e12656. https://doi.org/10.1111/ijn.12656

University of Pitesti. (2018, September 25). Instructions for authors. Retrieved 12 November 2019, from https://web.archive.org/web/20180925104637/http://efsupit.ro/index.php/instructions-to-authors

Ware, M. (2008). Peer review in scholarly journals: Perspective of the scholarly community - Results from an international study. Information Services and Use, 28(2), 109-112. https://doi.org/10.3233/ISU-20080568

Web of Science Group. (c2019). Web of Science journal evaluation process and selection criteria. Retrieved 3 November 2019, from https://clarivate.com/webofsciencegroup/journal-evaluation-process-andselection-criterial

Web of Science Group. (2019). Journal Citation Reports: Suppression policy. Retrieved 24 March 2019, from https://clarivate.com/webofsciencegroup/essays/journal-self-citation-jcr/

Wicherts, J. M. (2016). Peer review quality and transparency of the peer-review process in Open Access and subscription journals. PloS One, 11(1). https://doi.org/10.1371/journal.pone.0147913

Yan, J. R., Baldawi, H., Lex, J. R., Simchovich, G., Baisi, L.-P., Bozzo, A., \& Ghert, M. (2018). Predatory publishing in orthopaedic research. The Journal of Bone and Joint Surgery. American Volume, 100(21), e138(1-48). https://doi.org/10.2106/JBJS.17.01569

Yeates, S. (2017). After Beall's 'List of predatory publishers': Problems with the list and paths forward. Information Research, 22(4), paper rails1611. http://www.informationr.net/ir/22-4/rails/rails1611.html 